\title{
Paleoclimate histories improve access and sustainability in index insurance programs
}

\author{
Andrew R. Bell a,*, Daniel E. Osgood ${ }^{\text {b }}$, Benjamin I. Cook ${ }^{\text {c,e }}$, Kevin J. Anchukaitis c,f, \\ Geoffrey R. McCarney ${ }^{\mathrm{d}}$, Arthur M. Greene ${ }^{\mathrm{b}}$, Brendan M. Buckley ${ }^{\mathrm{c}}$, Edward R. Cook ${ }^{\mathrm{c}}$ \\ a International Food Policy Research Institute, Washington, DC 20006, USA \\ ${ }^{\mathrm{b}}$ International Research Institute for Climate and Society, The Earth Institute at Columbia University, Palisades, NY 10964, USA \\ ' Lamont-Doherty Earth Observatory of Columbia University, Palisades, NY 10964, USA \\ d School of International and Public Affairs, Columbia University, New York, NY 10027, USA \\ e NASA Goddard Institute for Space Studies, 2880 Broadway, New York, NY 10025, USA \\ ${ }^{\mathrm{f}}$ Woods Hole Oceanographic Institution, Woods Hole, MA 02543, USA
}

\section{A R T I C L E I N F O}

\section{Article history:}

Received 11 April 2012

Received in revised form 29 January 2013

Accepted 11 March 2013

\section{Keywords:}

Paleoclimate

Tree rings

Index insurance

Non-stationarity

Agriculture

\begin{abstract}
A B S T R A C T
Proxy-based climate reconstructions can extend instrumental records by hundreds of years, providing a wealth of climate information at high temporal resolution. To date, however, their usefulness for informing climate risk and variability in policy and social applications has been understudied. Here, we apply tree-ring based reconstructions of drought for the last 700 years in a climate index insurance framework to show that additional information from long climate reconstructions significantly improves our understanding of the underlying climate distributions and variability. We further show that this added information can be used to better characterize risk to insurance providers, in many cases providing meaningful reductions in long-term contract costs to farmers in stand-alone policies. The impact of uncertainty on insurance premiums can also be reduced when insurers diversify portfolios, and the availability of long-term climate information from tree rings across a broad geographic range provides an opportunity to characterize spatial correlation in climate risk across geographic regions. Our results are robust to the range of climate variability experienced over the last 400 years and in model simulations of the twenty-first century, even within the context of changing baselines due to low frequency variability and secular climate trends. These results demonstrate the utility of longer-term climate histories in index insurance applications. Furthermore, they make the case from a climatevariability perspective for the continued importance of such approaches to improving the instrumental climate record, even into a non-stationary climate future.
\end{abstract}

(c) 2013 Elsevier Ltd. All rights reserved.

\section{Introduction}

Droughts and other climate-related events have severe impacts on smallholder farmers in developing economies (e.g., Adamson and Bird, 2010; Kallis, 2008). Agricultural insurance plays an important role in allowing farmers to manage risk in high-income countries, but is largely unavailable in lower-income countries, where it is limited by implementation costs and the potential for perverse incentives to farmers (such as reducing inputs or destroying crops to increase the size of losses) (IRI, 2009). Thus, it is often the case that the farmers who are most vulnerable to climate risk lack access to insurance tools that could help to protect them.

\footnotetext{
* Corresponding author. Tel.: +1 2028624644

E-mail address: a.bell@cgiar.org (A.R. Bell).
}

Index insurance has the potential to solve many of the problems blocking access to insurance in lower-income countries (Barrett et al., 2007). By triggering payouts on an index (such as total seasonal rainfall, temperature, or soil moisture), it addresses perverse incentives and greatly reduces the costs of insuring smallholder farmers. Accordingly, index insurance has generated a great deal of interest in the development community, with dozens of ongoing pilot projects underway to determine if it is an affordable, viable tool for adaptation and poverty reduction (Hazell et al., 2010; Hellmuth et al., 2009), with the greatest development having occurred in India where millions of farmers hold contracts (Clarke et al., 2012), and in China where recent index insurance pilots have shown promise, following the introduction of a major insurance subsidy in 2007 and explosive growth in agricultural insurance provision (Hazell et al., 2010). However, a trade-off to the benefits of index insurance is that indices may have limited

0959-3780/\$ - see front matter (c) 2013 Elsevier Ltd. All rights reserved. http://dx.doi.org/10.1016/j.gloenvcha.2013.03.003 
accuracy in calibrating payouts to actual losses, an issue commonly known as basis risk. Furthermore, there are still challenges concerning both the supply and demand of index insurance for smallholder farmers that must be overcome.

For example, concerns have been raised in the literature that demand for index insurance among farmers may be too low (Banerjee and Duflo, 2011; Cole et al., 2009; Giné and Yang, 2009; Hazell et al., 2010), due to the degree of uninsured basis risk not covered by index contracts, as well as issues of trust, communication, consumer education, and price (Patt et al., 2010; Trærup, 2012). However, initial efforts to encourage demand are yielding results. Projects in the Horn of Africa have grown from hundreds to tens of thousands of farms over only two to three years (Oxfam, 2011; Syngenta Foundation, 2011) while in India, subsidized index insurance had expanded to include nearly twenty million farmers by 2008 (Mahul et al., 2012). Studies on Ethiopia (Meze-Hausken et al., 2009) and Tanzania (Trærup, 2012) further suggest that shifting the scale at which insurance is applied and allowing spatial pooling of risk among networks of farmers has potential to overcome barriers of trust and perceived risks, and further enhance demand. On the supply side, there is concern that the science underlying the construction of these indices is not sufficiently strong to scale up insurance programs. The lack of suitable climate data, particularly in developing countries, therefore remains a key constraint to the development of robust insurance products (Brown et al., 2011; Norton et al., 2011).

Lacking sufficient climate data, insurance providers are unable to accurately price their products, forcing them to price contracts conservatively to ensure that they can be honored. This leads to premiums that are prohibitively expensive (Meze-Hausken et al., 2009), or to insurance companies not being willing to offer any product at all (IFC, 2010). Moreover, if existing climate records are insufficient to adequately characterize climatic variability, then the premium in a given period may reflect over- or underestimates of the probability of a payout, so that they are again priced inaccurately.

The risk of using shorter climate records to determine index insurance premiums is therefore that the price will not correspond well to the underlying climate risk, limiting access to insurance products for poor farmers (if the premium is set too high), or jeopardizing the sustainability of the insurance project (if the premium is set too low). These problems have been central hurdles faced by major index insurance efforts (Hazell et al., 2010).

Paleoclimate records have the potential to improve the accuracy of index insurance pricing and therefore improve access to, and the sustainability of, climate insurance for poor farmers. Annual growth rings of trees, for example, provide millenniumscale, annually-resolved records of climate that can be used to estimate past climate variability and derive uncertainties for those estimates. Trees are ubiquitous over much of the planet, so that networks of tree ring chronologies can be used to develop objective estimates of climate variability in both space and time - providing improved characterization of local hydroclimatic variability, the return interval of extrema, and the possible range of climate anomalies. Temperature or moisture stresses manifest as reductions in radial growth, so that the relative width of tree rings can provide a history of environmental conditions (in particular and of interest in this study, drought) of potential value in natural resource decision-making.

The notion that tree rings could inform decision-making is decades old, with work since the 1930s in the US Southwest linking tree rings to streamflow (Hardman and Reil, 1936; Stockton and Jacoby, 1976) and reservoir reliability (Potts, 1962), with more recent application in ecosystem (e.g., Swetnam et al., 1999; Willis et al., 2010) and water management (e.g., Woodhouse and Lukas,
2006). The history of tree rings in the water management context specifically is well reviewed by Meko and Woodhouse (2011). However, the potential for application in a risk management context has only more recently been developed (e.g., Bell et al., 2011). Using the Monsoon Asia Drought Atlas (MADA) (Cook et al., 2010a) and North American Drought Atlas (NADA) (Cook et al., 2010b), this study makes an important first connection between paleoclimate variability and modern risk management in agriculture by applying tree-ring-based climate reconstructions to the pricing of index insurance contracts. In the following sections we apply tree-ring data to estimating prices in a model index insurance contract, and discuss the implications of this simple example for established and new index insurance schemes.

\section{Methods}

The price of an index insurance premium is shaped by two components: first, the expected value of the payout; and second, the costs the insurer bears in administering the contract, capturing an economic profit, and borrowing the 'value at risk' of the contract. Both of these price components can be improved (made more accurate) by the use of richer data sets more representative of true climate variability. Our contracts are priced on the Palmer Drought Severity Index (PDSI), a drought measure widely used in agriculture (Dai et al., 2004; Heim, 2002) that expresses soil moisture as a normalized departure from a locally-averaged water balance. Tree rings have previously been used to reconstruct other environmental signals such as temperature or stream-flow, upon which corresponding climate index products could be developed.

Formally, the price premium is calculated as:

$C_{\text {contract }}=E(R)+r \cdot[V A R-E(R)]$

where $E(R)$ is the expected payout, VAR is the 'value at risk' - the maximum expected payout (such as for a 1 in 100 year event), and $r$ is a target rate of return or the opportunity cost of funds for the insurer. Administrative costs other than the VAR are not sensitive to the use of climate information and are not treated explicitly here for simplicity. This is a simple and stylized pricing formula utilized in many index insurance pilots and in World Bank Index insurance training materials (see for example, IRI, 2009; Osgood et al., 2007); for the purposes of our analysis it provides a clear view into how the two key drivers of contract price (expected payout and value at risk) respond to changes in available climate information. The variable $r$ is the interest rate paid by the insurer; because in an index insurance program, all insured contracts can be expected to pay out at the same time (via spatially pervasive drought), the insurer cannot count on premiums paid from other contracts to cover payouts and must instead borrow enough money to cover the maximum payout. In this study we adopt a typical linear payout structure, with payouts triggered at some dry PDSI $Z_{\text {trigger }}$ and increasing up to the largest possible payout at the exit PDSI $Z_{\text {exit }}$ :

$R=\max \left(0, \min \left(\frac{Z_{\text {trigger }}-Z}{Z_{\text {trigger }}-Z_{\text {exit }}}, 1\right)\right) \cdot R_{\text {exit }}$

where $Z$ is the observed PDSI and $R_{\text {exit }}$ is the payout at $Z_{\text {exit. }}$. The expected payout for the contract in a given year is calculated as the integral:

$E(R)=\int_{-\infty}^{Z_{\text {trigger }}} p(Z) \cdot \max \left(0, \min \left(\frac{Z_{\text {trigger }}-Z}{Z_{\text {trigger }}-Z_{\text {exit }}}, 1\right)\right) \cdot R_{\text {exit }}$

where $p(Z)$ is the probability of a PDSI value of $Z$, and the bounds $-\infty$ to $Z_{\text {trigger }}$ reflect the PDSI range over which the insurance contract pays out due to drought. The probability $p(Z)$ is drawn from the Gaussian distribution $(\mu, \sigma)$ estimated from the climate 
history, with error $\left(\delta_{\mu}, \delta_{\sigma}\right)$. In this study, conservatism in estimating VAR is represented by calculating VAR as:

$V A R=\operatorname{MAX}\left(0, \min \left(\frac{Z_{\text {trigger }}-Z_{0.01}^{*}}{Z_{\text {trigger }}-Z_{\text {exit }}}, 1\right)\right) \cdot R_{\text {exit }}$

where $p\left(Z_{0.01}^{*}\right)=0.01$ from the distribution $\left(\mu-2 \delta_{\mu}, \sigma+2 \delta_{\sigma}\right)$, i.e., the lower $95 \%$ confidence limit for the expected 1 -in-100 year event. While insurance programs in practice may be more or less conservative in estimating the $V A R$, this formula captures a common dependence on uncertainty - the less certain the estimate of the VAR, the more the estimate may be inflated to avoid exceedance. We demonstrate in our sensitivity analysis that our findings - the relative benefit of using longer climate series - are robust to different choices for the VAR calculation (75\% and 50\% confidence limits in Figures S49, S50 respectively).

We calculated the insurance price for a contract with a $Z_{\text {trigger }}$ of PDSI -2 and $Z_{\text {exit }}$ of PDSI -6 for each of the 400 years from 1606 to 2005. The trigger PDSI of -2 corresponds to around 1-in-10-year payouts on average across the MADA and NADA, with payouts slightly more frequent in the NADA (around 1-in-9-years) than the MADA (around 1-in-11-years) (Figures S46-48 show results from our sensitivity analysis varying the trigger and exit PDSI conditions). For each year, we varied the number of years of climate history used to estimate the price from 20 years up to 300 years (i.e., to calculate a price in 1606, varying the first year of climate history from 1586 back to 1306). For each of these 400 years we also calculated the actual payout of the insurance contract. We do not present a simple average of results over the 400 -year period, because that is not a quantity of interest in the agricultural context. Typical agricultural careers are built over a span of a few decades, so we instead calculate 30-year averages of our results over the 400-year span of data, and present the average of these outputs. The results thus show average expectations over the course of a 30-year agricultural career, given the range of observed climate variability over the last 400 years (as opposed to the expectation over the course of an agricultural career spanning from 1606 to the present day). While some holdings might remain in families for many generations, the choice of a 30 -year average is made to demonstrate benefits that may accrue to an individual without needing to purchase contracts continually over a long, inter-generational period.

For data, we use chronologies of the Palmer Drought Severity Index (PDSI) derived from the Monsoon Asia Drought Atlas (MADA) and the North American Drought Atlas (NADA). The MADA is a 2.5degree gridded PDSI database derived from 327 tree-ring chronologies spanning all of monsoon Asia with a common period of 706 years (from 1300 to 2005) (Cook et al., 2010a); the NADA is a 2.5-degree gridded PDSI database from 835 tree-ring chronologies spanning Central Mexico to Northern Canada for the past 2005 years (Cook et al., 2010b).

Data for the 20th and 21st century comparisons were derived from 3 randomly-selected simulation runs $(0021,0025$, and 0026) from the ocean-atmosphere coupled general circulation model ECHAM5-MPIOM (Jungclaus et al., 2010). PDSI was calculated from temperature and precipitation fields (Palmer, 1965; Touchan et al., 2011 ), and the 21 st century was detrended using breakpoints at 2000, 2020, 2040, 2060, and 2080.

\section{Results}

We now demonstrate the impacts that even simple uses of paleoclimate data can have on index insurance pricing. Prices in our simulations are determined using climate histories of varying length, and are calculated using a commonly-applied linear pricing scheme (IRI, 2009; Osgood et al., 2007), in which contracts pay indemnities when the climate index drops below a 'trigger' value. Under this pricing scheme, payouts increase linearly with the severity of the climate condition until a maximum payout is reached at an 'exit' value (see Section 2). Our contracts are priced on the Palmer Drought Severity Index (PDSI), a drought measure widely used in agriculture (Dai et al., 2004; Heim, 2002) that expresses soil moisture as a normalized departure from a locallyaveraged water balance.

The price of the index insurance contract has two parts - the cost of financing the expected payout, and a 'loading cost'. Index insurance is meant to capture systematic climatic risk for a particular region, and so unlike traditional insurance programs, all contracts subject to the same climate will need to be paid out at once. Part of the function of the loading cost is to cover this risk to the insurer by covering the cost of keeping the maximum expected payout (the 'value at risk' or VAR) on hand. Additionally, loading costs usually include administrative costs and an economic profit to the lender.

Typically, and in this study, the VAR is the payout associated with the 1-in-100 year drought event (Osgood and Shirley, 2010). Where additional climate data leads to downward revisions in the assumed VAR, insurance contract prices may drop. However, if the VAR is reduced too much, the rate at which payouts exceed the VAR will rise, putting the insurer at risk (since they will be more likely to be caught without enough capital on hand). Longer-term climate information can reduce uncertainty and improve accuracy in estimating the distribution of climate events, and thus, more specifically, the VAR.

Thus, the value of extended paleoclimate data for index insurance programs is realized when it (i) better estimates the expected payout or (ii) facilitates a reduction in VAR (and thus in contract price) without significantly raising the risk to the insurer. The change in average net cost (average over a 30-year career of payouts minus premiums, expressed as an annual cost - see Section 2) to insurance contract holders (from increasing the length of climate data from 20 years to 300 years) is shown for all points covered by the MADA and NADA (Fig. 1), within which we have outlined seven regions of agricultural importance: (1) North India, (2) Mongolia, (3) Indochina, (4) US Southwest, (5) Canadian Prairies, (6) Central Mexico, and (7) the US Cornbelt. While index insurance products may have lower additive value to the developed-country agricultural areas in this group, we include them to demonstrate the robustness of our results across different patterns of climate variability. For the outlined regions we also show spatially averaged, temporally-resolved estimates of prices and payouts using different lengths of climate history in the Electronic Supplementary Material (ESM, Figures S31-S37).

Across much of the MADA and NADA landscape, we observe reductions in the average insurance contract price and in the average net cost to the insurance contract holder as the length of climate history used is increased (Fig. 1). North India and Indochina stand out at 300 years of climate data with large average net cost reductions over the course of a 30 -year agricultural career (Fig. 2) though as we discuss in the following sections, the actual additivity of an increase in data to an already diverse portfolio would likely be less. The reasons for these observed reductions in the average contract price and average net cost are twofold - and follow the reasoning laid out above. First, costs imposed on the farmer by uncertainty and inaccuracies in the expected payout are reduced as longer climate histories lead to improved estimates of payout probabilities. Secondly, reductions in the VAR are realized, and are accompanied by only modest increases in exceedance rates (less than 0.2 additional exceedances per 30 -year period for Indochina, or less than once in 150 years), indicating great potential for insurers to reduce uncertainty embedded in prices and thereby make programs more accessible, without incurring unacceptable 


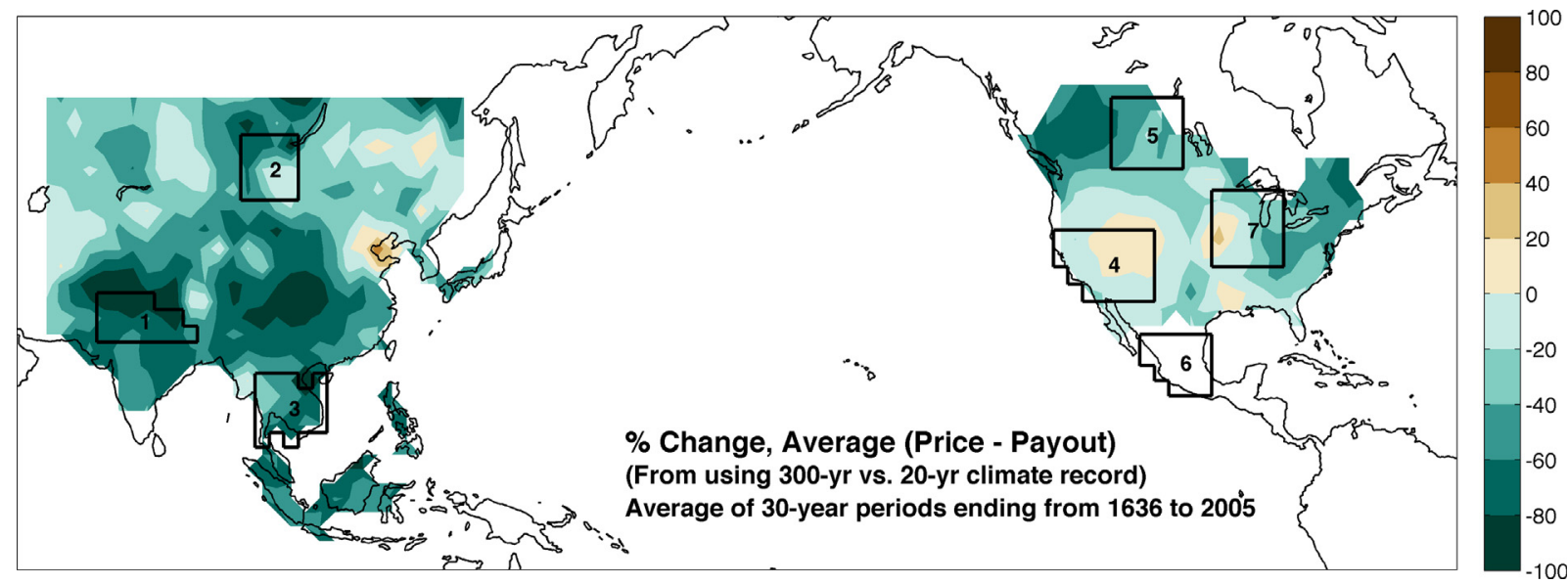

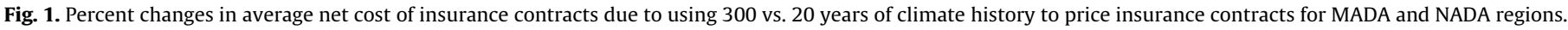
Results show the average net cost over a 30-year agricultural career, averaged again across all 30 -year periods within the climate history from 1636 to 2005 .

levels of risk (Fig. 3). This result is relatively stable to changes in trigger and exit conditions (and thus to the designed frequency of payouts), with reductions in net cost appearing to be greater for lower (more negative) trigger and exit conditions (Figures S4648). Put simply, the more that the range between trigger and exit coincides with the tails of extreme drought that are better predicted with longer time series, the more valuable these longer time series become.

The length of additional climate history needed to provide improved information on climate variability and risk varies by region. Parameter estimates for Indochina and North India improve continuously and smoothly with additional data, although improvement in North India begins to plateau around 100-200 years of data (ESM, Figure S38). Conversely, parameter estimates for the US Southwest and the Cornbelt do not begin to improve until around several centuries of paleoclimate history or more have been used (ESM, Figure S1-S10, S45). These specific cross-region differences are due to differences in the regional climate spectra. Variance in much of Monsoon Asia, including India and Indochina, is concentrated in the relatively high frequency ENSO band (3-5 years) (ESM, Figure S38, S40). Progressively including more data at these sites rapidly improves the sampling of this relatively high frequency variability, quickly improving parameter estimates. Conversely, the US Southwest and Cornbelt regions have significant spectral power at decadal and multi-decadal frequencies (ESM, Figure S38-S44). This necessitates the use of longer climate histories (300 or more years) to fully capture and characterize the full range of low-frequency variability, and thus begin to realize improvements in the parameter estimates.

As a diagnostic check of the link between spectral power and the length of data required to realize improvements, we applied a high-pass filter to the PDSI records in the US Southwest to remove variability below certain frequency thresholds (ESM, Figure S45). If decadal and multi-decadal processes drive the need for longer time series, the high-pass filtered US Southwest data should show price gains with shorter histories. Applying our analysis to the new high frequency series, we are able to realize insurance contract gains comparable to Indochina or north India, and that begin with as little as 60 years of additional data - in short, regions whose climate exhibits higher spectral power at low frequencies will require longer data histories to be adequately captured by this framework and for price improvements to be realized.

While across much of our system we observed reductions in longterm cost to the contract holder through the use of longer climate series, it is important to assert that additional climate information will not (and should not) do so in all cases. Mechanistically, there are two distinct effects of additional climate information on price - the reduction of uncertainty in estimation of the $V A R$, and the improved estimation of climate risk by better characterization of the distribution of climate events. In the case of the former, reduction of uncertainty will manifest largely as a reduction in the VAR and a lower cost of borrowing passed on to the contract holder. However, in the case of the latter, improved information may not always reduce costs for the contract holder - they may, for example, reveal greater likelihood of drought and the need to capture greater risk in the contract premium. Even in these cases however, the improved capacity to estimate risk is a benefit to the insurance provider that leaves them better positioned to offer an insurance product. Thus, paleoclimate data have potential not only to increase access but also the sustainability of insurance programs.

\subsection{Predicting under non-stationary climates}

Our analysis has demonstrated the potential for paleoclimate data to inform index insurance pricing under the range of climate variability experienced up to the present. However, it is crucial that any framework that uses paleo- or historical analog information be transportable to situations in which the background climate state is changing or non-stationary (Milly et al., 2008), including potential future climates that will be dominated by increased greenhouse gas forcing. Our diagnostic analysis of spectral power across the different regions in our study provides some initial insight toward answering this question. Future climate change at centennial timescales will be dominated by secular trends associated with anthropogenic greenhouse gas forcing which, in our analysis, can be interpreted as very low-frequency variability (IPCC, 2007). If the higher-frequency variability (inter-annual to decadal) continues to be dominated by variability internal to the climate system, and thus retains a similar structure moving into the 21 st century, a relation could be made from this future climate to the past centuries of climate history by removing low frequency components from paleoclimate data and inserting low-frequency processes indicated by climate change models.

In such an approach, the low-frequency variability removed from the climate can be incorporated as a shift (bias) to the climate distribution evaluated from the detrended climate history. If the structure of the higher-frequency variability is not preserved, then such a strategy will be unsuccessful, and more sophisticated innovations will be necessary.

Because it is an open question whether high-frequency variability will be maintained in the future, we perform a demonstration of concept to investigate if there is any scope for 


\section{Indochina Average}

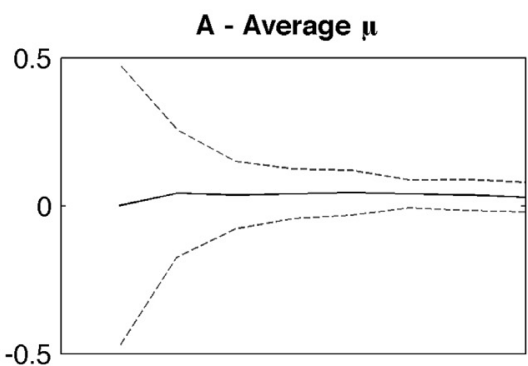

C - Value at Risk

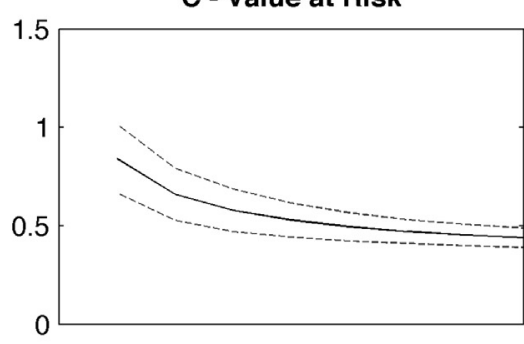

E - Average Price

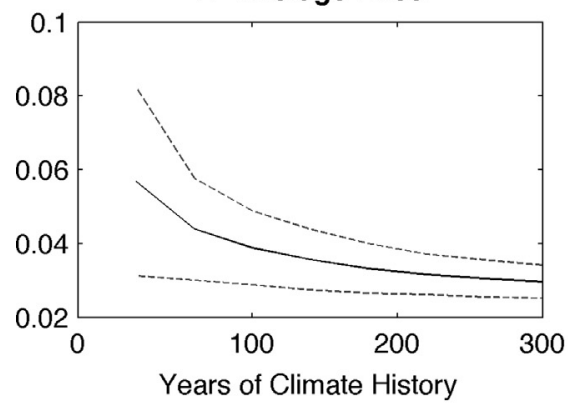

B - Average o

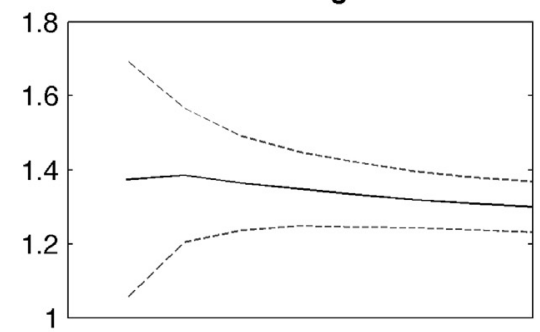

D - Average Exceedance of VAR in 30-yr period

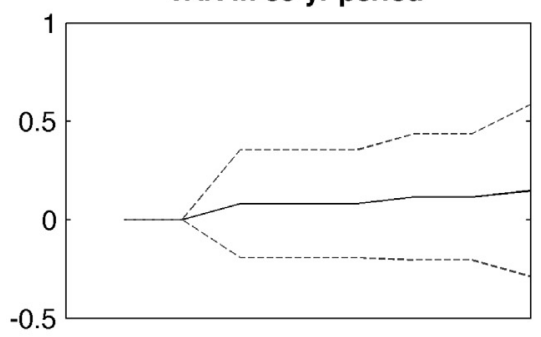

F - Average, 30-yr Avg (Payout - Price)

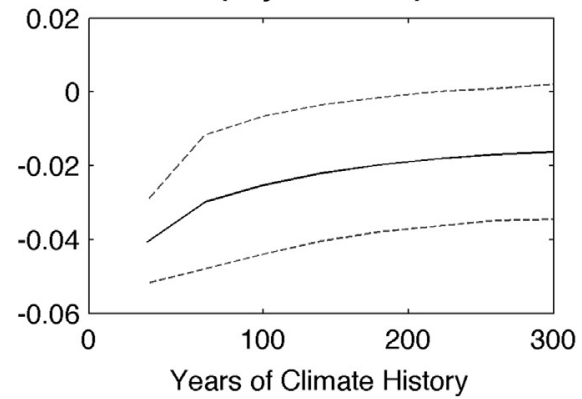

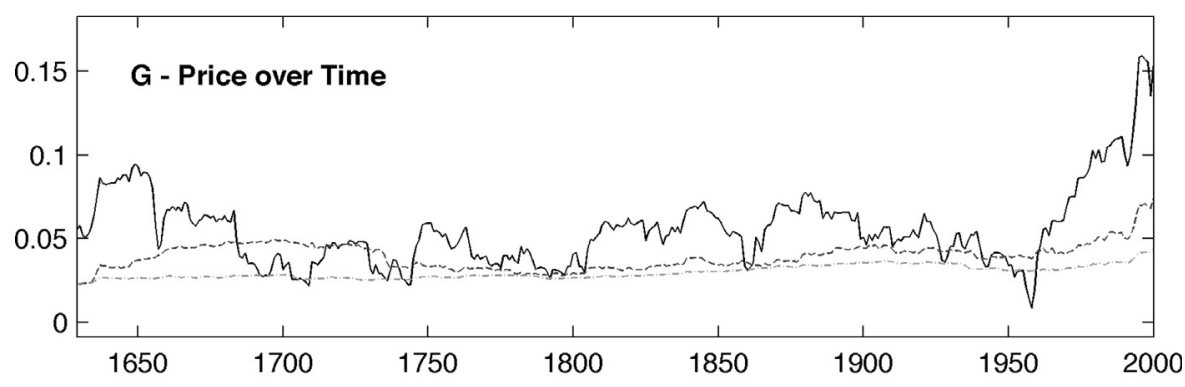

Using 20 years _.-.- Using 100 years _........ Using 300 years

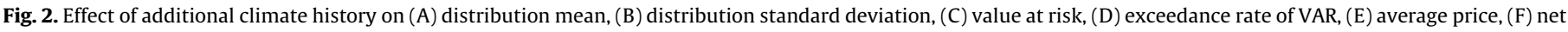
cost to contract holder, and $(G)$ price history, for Indochina region. Black line in A-F shows mean value; dashed lines show \pm 1 standard deviation.

such an approach. We utilize perhaps the simplest low-frequency mapping possible, a linear trend, not because we are arguing that it is an appropriate model, but to make our test more conservative. If there appears to be scope for moving forward even when using the most basic tools, more sophisticated approaches may perform better.

Since information on future climate is not directly available, we test the approach using sources of information currently being used to predict future climate. We apply our analyses to output from a continuous ( 800 C.E. to 2100 C.E.) forced 3-member ensemble simulation of the ocean-atmosphere coupled general circulation model ECHAM5-MPIOM (Jungclaus et al., 2010). From these runs, we calculate monthly PDSI comparable to the MADA and NADA drought atlases, and apply our analysis framework to all global land areas. The long-term secular changes induced by increasing greenhouse gas forcing clearly manifest as a rise in lowfrequency (greater than 100 years) variability moving into the $21 \mathrm{st}$ century (ESM, Figure S53). We linearly detrend the twenty-first century PDSI to remove these changes, preserving the underlying year-to-year variance. Comparable performance of our framework 

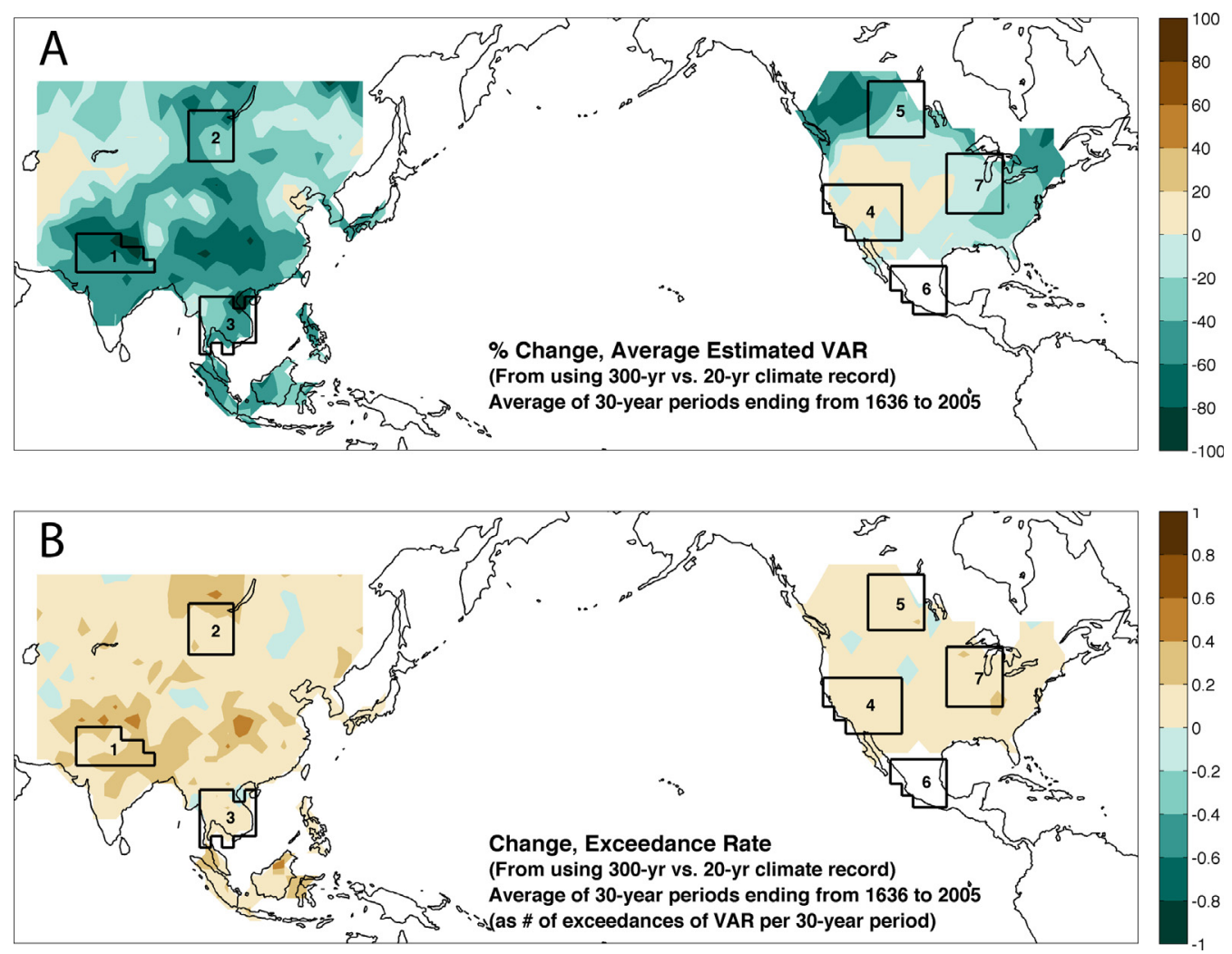

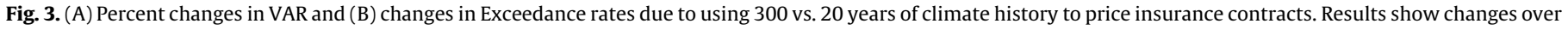
a 30-year agricultural career, averaged again across all 30-year periods within the climate history from 1636 to 2005.

on this dataset across the 20th and 21st centuries would support the notion that long-term climate histories can remain useful, via simple transformations, into the coming decades of non-stationary climate.

We find in this particular case that the strategy is successful. Averaging across the 3 ensemble members, we find that roughly $40 \%$ of the land grid points (excluding Antarctica) realize changes in index insurance pricing (again, for a stand-alone contract) of between 0 and $100 \%$ across the 20th and 21st centuries, and less than $15 \%$ of grid points realize reductions greater than $100 \%$ (implying a net gain to the contract holder and an unsustainable product) due to improved estimates of climate variability using longer-term climate histories (ESM, Figures S60-61). Removed secular trends can be re-incorporated by shifting the expected distribution up or down, modifying the absolute price but, crucially, preserving the changes in price demonstrated here. Therefore it is possible that there is scope for mapping past statistics into future pricing in a non-stationary climate using relatively simple approaches applied to climate model outputs.

Making inference based on these results requires caution on several fronts. First, we do not expect the GCM-generated PDSI to have precisely the same statistics as the real world PDSI and the reconstructed MADA and NADA products. Secondly, our ability to properly condition models of future drought on past events is still developing (e.g., van der Schrier et al., 2013), suggesting these predictions may have room to be updated. Thirdly, we don't necessarily expect insurance parameters to remain constant under a longer-term shift in mean climate - a shifting mean may require a concomitant shift in trigger, exit, or maximum payout conditions for the product to remain viable. However, these results do provide a framework in which to explore our methodology in the context of natural and anthropogenic climate change. The key message that these data deliver is the notion that the interannual structure of climate variability may be sufficiently preserved going forward into the twenty-first century such that historical and paleo-analog approaches remain viable.

\subsection{Diversifying a portfolio}

A critical caveat in the benefits to longer climate histories we suggest are possible is that our example looks only at one contract. In a mature insurance program, the provider will have contract holders across a wide region with less-than-perfectly correlated climate risks; the provider may also have a range of other insurance products and investments with risks uncorrelated with climate at all, reducing the barrier to insurance provision posed by the VAR.

In the case of the former, our gridded long-term dataset provides a unique opportunity to investigate what the benefits of diversifying a portfolio geographically (with the same insurance product) might be. Using the same results developed above, we look at the distribution of total annual payouts and calculated total $V A R$ as a function of portfolio size. We randomly draw portfolios from 1 to 20 contracts in size (each contract being based on a different randomly drawn point from the MADA or NADA dataset), replicating each portfolio size 200 times and drawing on the last 300 years of data in each replication. Because our dataset is finite in size, sampling ever larger portfolios begins to strongly violate the assumption that portfolios are independent and identically distributed, so we limit our portfolio size to 20 contracts.

We draw a few key insights comparing calculated VAR distributions and their relationship to payouts from looking at these different portfolio sizes and using either 20-year or 300-year data histories (Figures S62-69). First, the distribution of payouts (independently of how much data is used to calculate prices) shifts from bimodal (skewed toward 0 with a small peak of higher 
payouts) toward a bell shape centered on the long-term mean payout, demonstrating the desired outcome of diversification. Similarly, the distribution of the VAR shifts toward a distribution centered on its mean which in turn is markedly lower when longer climate histories are used. Finally, we can observe that the distribution of the payout/VAR ratio shifts as well, with increased portfolio size decreasing the number of instances of exceedance (payout/VAR $>1$ ).

In sum, in a mature index insurance program, some of the benefits of using longer-term climate series in reducing VAR (by reducing uncertainty) are duplicated and perhaps exceeded by the reductions in VAR from diversifying the portfolio (by spreading risk). This stated, a reduction in the mean VAR remains a demonstrable benefit to the inclusion of longer data series.

\section{So what? Implications for existing and new insurance programs}

Our analysis shows how paleoclimate data can provide additional information to help insurers accurately price index insurance contracts, increasing the accessibility of these insurance products to previously underserved areas. In our test period, longer climate histories reduced the long-term average net cost of insurance contracts across Asia and many parts of North America by reducing the uncertainty in the climate distribution and through accompanying shifts to the expected payout and the size of the value at risk. Better characterization of the distribution of climate events with longer time series - while not necessarily reducing costs to the contract holder - can also be beneficial by providing a better signal of risk to both the insurance provider and contract holder alike. The length of climate history necessary to bring changes in contract parameters depends upon the specific regional climate; regions with significant low-frequency variability (decadal and longer) require longer climate histories before the characterization of the climate distribution can be improved. The results we show are robust to the range of climate variability experienced over the last four centuries, and clearly show the benefits that paleoclimate data can offer to insurance providers making decisions on contract prices. Further, using state-of-the-art model projections of future climate, we show that inter-annual climate variability in at least in one suite of climate model simulations is sufficiently preserved, suggesting that these methods can be expected to retain value in the decades of development to come.

There are several factors that must be considered in relating the results of our numerical example to the practical world of insurance schemes. The most significant of these is that in practice, insurance providers are able diversify portfolios across a number of products and avoid holding the balance of $[V A R-E(R)]$ for each policy; additionally, much of the risk held by these providers can be transferred to international reinsurers, for whom the risks posed by weather index insurance programs is not likely to be tightly correlated with their peak risk, and thus not pose great demands for additional capital. The consequence of this is that for a mature insurance program, as we have illustrated above, the long-term benefits of added climate history are likely to be significantly lower than the striking results demonstrated in our study, perhaps by an order of magnitude. That stated, an improvement in pricing - whether by a large or small fraction - can play an important role in augmenting demand for insurance products among poorer farmers, and helping programs to remain sustainable. Additionally, the effect of added climate history may prove more pronounced in the kinds of early pilot studies necessary to generate demand, which may not have the same capacity to diversify their risk as mature insurance programs.
A second consideration is the range in pricing schemes and estimations of uncertainty applied across operational insurance schemes. Our study implemented a particular pricing formula, and a particular means of addressing uncertainty. Pricing formulas may be non-linear, and may be calibrated to provide payouts at greater or lower frequencies than demonstrated in our example. Adjustments for uncertainty may be more or less elastic to changes in available information than in our example. In systems where VAR calculation is less sensitive to reduction in uncertainty, the component of the shift in price attributable to a reduced VAR will be less significant (see Figures S49-50 in the sensitivity analysis for different calculation of VAR, and S51-52 for impacts of changing $r$ - and thus the weight of the VAR in contract pricing). It is not feasible to analyze the role of climate information across the range of current practices in index insurance schemes; rather, we use the idealized example in this study to demonstrate the mechanisms through which paleoclimate date can improve pricing, and implore researchers and practitioners to consider the role it may play in other candidate systems that depart from this particular implementation.

\section{Final remarks}

Improved historical records have proven extremely valuable for reducing the costs of insurance to low-income farmers in developing countries (Osgood and Shirley, 2010), and even longer paleoclimate records have immense potential to catalyze the creation of much less expensive products and make insurance feasible where it was otherwise impossible. Currently, index insurance is transitioning from small-scale pilots in carefully selected sites to large-scale implementations. Paleoclimate records can provide critical, long-term information to this transition, helping build a foundation that allows science-based prices as well as the identification of climate threats that are not evident in shortterm weather station and satellite-based datasets.

When bundled with loans, insurance programs can also become vehicles for the extension of agricultural credit to a broader community (Barnett et al., 2008). By improving pricing, paleoclimate histories may therefore also help to improve access to credit via more affordable insurance products. Bundling agricultural insurance with credit contracts can both help to encourage farmers to take loans and increase the willingness of lenders to extend credit to lower-income farmers, since the insurance lowers the probability that farmers will default due to climatic risk.

We do not intend through these results to suggest that we have a solution to the complex issue of forecasting a climate under both natural and anthropogenic forcing. Rather, we only hope to demonstrate a valuable link that can be made between past, present, and future climate for risk management purposes; one that will continue to be valuable under a non-stationary climate, and that can continue to be developed in the iterative process of creating usable science (Dilling and Lemos, 2011). Improved use of this link in future research might include an improved estimation of the VAR using extreme value theory (EVT), an exercise only possible with the larger sample size afforded by the paleoclimate data.

The key requirements in linking paleoclimate histories to insurance (and other) development programs are the availability of data (1) with sufficient temporal resolution and (2) co-located with the region of interest. Temporally, tree ring based climate reconstructions serve these needs especially well, providing precisely dated and annually resolved information. Additionally, trees are widely distributed - the MADA was based on chronologies spanning the entirety of monsoon Asia, the NADA on chronologies spanning North America, while other studies have demonstrated the wealth of climate information stored in trees in Africa (e.g., Touchan et al., 2008; Wils et al., 2011) and Latin and 
South America (e.g., Christie et al., 2011; Urrutia et al., 2011). These latter regions have historically received less attention in tree-ring research, but it is our hope that a clear link between tree-ring data and risk management in agriculture will bring new attention to data collection in Africa and South America. Treering based paleoclimate records may thus have wide applicability in increasing the availability of affordable, sustainable index insurance.

\section{Acknowledgements}

This work was funded by NSF grant AGS 0908971. We also gratefully acknowledge Dr. Johann Jungclaus for making available the ECHAM5-MPIOM simulation runs.

\section{Appendix A. Supplementary data}

Supplementary data associated with this article can be found, in the online version, at doi:10.1016/j.gloenvcha.2013.03.003.

\section{References}

Adamson, P., Bird, J., 2010. The Mekong: a drought-prone tropical environment? Water Resources Development 26, 579-594.

Banerjee, A.V., Duflo, E., 2011. Poor Economics: A Radical Rethinking of the Way to Fight Global Poverty. Public Affairs, Philadelphia, USA.

Barnett, B.J., Barrett, C.B., Skees, J.R., 2008. Poverty traps and index-based risk transfer products. World Development 36, 1766-1785.

Barrett, C.B., Barnett, B.J., Carter, M.R., Chantarat, S., Hansen, J.W., Mude, A.G., Osgood, D.E., Skees, J.R., Turvey, C.G., Ward, M.N., 2007. Poverty Traps and Climate Risk: Limitations and Opportunities of Index-Based Risk Financing. IRI Technical Report 07-03.

Bell, A.R., Cook, B.I., Anchukaitis, K.J., Buckley, B.M., Cook, E.R., 2011. Repurposing climate reconstructions for drought prediction in Southeast Asia. Climatic Change 106, 691-698.

Brown, M., Osgood, D., Carriquiry, M., 2011. Science-based insurance. Nature Geoscience 4, 213-214.

Christie, D.A., Boninsegna, J.A., Cleaveland, M.K., Lara, A., Le Quesne, C., Morales, M.S., Mudelsee, M., Stahle, D.W., Villalba, R., 2011. Aridity changes in the Temperate-Mediterranean transition of the Andes since ad 1346 reconstructed from tree-rings. Climate Dynamics 36, 1505-1521.

Clarke, D.J., Mahul, O., Rao, K.N., Verma, N., 2012. Weather Based Crop Insurance in India, Policy Research Working Paper. World Bank, Washington, DC p. 31.

Cole, S., Giné, X., Tobacman, J., Topalova, P., Townsend, R., Vickery, J., 2009. Barriers to Household Risk Management: Evidence from India. Federal Reserve Bank of New York, New York.

Cook, E.R., Anchukaitis, K.J., Buckley, B.M., D’Arrigo, R.D., Jacoby, G.C., Wright, W.E., 2010a. Asian monsoon failure and megadrought during the last millennium. Science 328, 4.

Cook, E.R., Seager, R., Heim, R.R., Vose, R.S., Herweijer, C., Woodhouse, C., 2010b. Megadroughts in North America: placing IPCC projections of hydroclimatic change in a long-term palaeoclimate context. Journal of Quaternary Science 25, 48-61.

Dai, A., Trenberth, K.E., Qian, T.T., 2004. A global dataset of Palmer Drought Severity Index for 1870-2002: relationship with soil moisture and effects of surface warming. Journal of Hydrometeorology 5, 1117-1130.

Dilling, L., Lemos, M.C., 2011. Creating usable science: opportunities and constraints for climate knowledge use and their implications for science policy. Global Environmental Change 21, 680-689.

Giné, X., Yang, D., 2009. Insurance, credit, and technology adoption: field experimental evidence from Malawi. Journal of Development Economics 89, 1-11.

Hardman, G., Reil, O., 1936. The relationship between tree-growth and stream runoff in the Truckee River basin, California-Nevada. Agricultural Experiment Station, Bulletin 141, 38.

Hazell, P., Anderson, J., Balzer, N., Clemmensen, A., Hess, U., Rispoli, F., 2010. The Potential for Scale and Sustainability in Weather Index Insurance for Agriculture and Rural Livelihoods. IFAD, Rome.

Heim, R.R., 2002. A review of twentieth-century drought indices used in the United States. Bulletin of the American Meteorological Society 83, 1149-1165.
Hellmuth, M.E., Osgood, D.E., Hess, U., Moorhead, A., Bhojwani, H. (Eds.), 2009 Index Insurance and Climate Risk: Prospects for Development and Disaster Management, Climate and Society No. 2. International Research Institute for Climate and Society (IRI), Columbia University, New York, USA.

IFC, 2010. Weather Index Insurance for Maize Production in Eastern Indonesia. International Finance Corporation, Jakarta, Indonesia.

IPCC, 2007. Contribution of Working Group I to the Fourth Assessment Report of the Intergovernmental Panel on Climate Change 2007. Cambridge University Press, Cambridge, United Kingdom/New York, NY, USA

IRI, 2009. Designing Index-based Weather Insurance for Farmers in Adiha, Ethiopia. International Research Institute for Climate and Society, Earth Institute, Columbia University, New York, USA.

Jungclaus, J., Lorenz, S., Timmreck, C., Reick, C., Brovkin, V., Six, K., Segschneider, J., Giorgetta, M., Crowley, T., Pongratz, J., others, 2010. Climate and carbon-cycle variability over the last millennium. Climate of the Past 6 723-737.

Kallis, G., 2008. Droughts. Annual Review of Environment and Resources 33, 85-118.

Mahul, O., Verma, N., Clarke, D.J., 2012. Improving Farmers' Access to Agricultura Insurance in India. Policy Research Working Paper. Washington, DC, World Bank: 22 pp.

Meko, D.M., Woodhouse, C., 2011. Application of streamflow reconstruction to water resources management. In: Hughes, M., Swetnam, T., Diaz, H. (Eds.), Dendroclimatology: Progress and Prospects. Springer, pp. 231-261.

Meze-Hausken, E., Patt, A., Fritz, S., 2009. Reducing climate risk for micro-insurance providers in Africa: a case study of Ethiopia. Global Environmental Change 19, 66-73.

Milly, P.C.D., Betancourt, J., Falkenmark, M., Hirsch, R.M., Kundzewicz, Z.W., Lettenmaier, D.P., Stouffer, R.J., 2008. Stationarity is dead: whither water management? Science 319 (5863), 573.

Osgood, D.E, McLaurin, M., Carriquiry, M., Mishra, A., Fiondella, F., Hansen, J., Peterson, N., and Ward, N., 2007. Designing Weather Insurance Contracts for Farmers in Malawi, Tanzania, and Kenya, Final Report to the Commodity Risk Management Group, ARD, World Bank. International Research Institute for Climate and Society (IRI), Columbia University, New York, USA.

Osgood, D., Shirley, K., 2010. The value of information in index insurance for farmers in Africa.

Oxfam, 2011. Horn of Africa Risk Transfer for Adaptation: HARITA quarterly report: October 2011-December 2011. Rural Resilience Series. Oxfam America. Boston, MA.

Palmer, W.C., 1965. Meteorological Drought. Research Paper No. 45. US Department of Commerce Weather Bureau.

Patt, A., Suarez, P., Hess, U., 2010. How do small-holders understand insurance, and how much do they want it? Evidence from Africa. Global Environmental Change 20, 153-161.

Potts, H., 1962. A 600-year record of drought recurrences. In: First Water Resources Engineering Conference, American Society of Civil Engineers, Omaha, Nebraska.

Stockton, C.W., Jacoby, G.C., 1976. Long-Term Surface Water Supply and Streamflow Levels in the Upper Colorado River Basin. Institute of Geophysics and Planetary Physics, University of California.

Swetnam, T.W., Allen, C.D., Betancourt, J.L., 1999. Applied historical ecology: using the past to manage for the future. Ecological Applications 9, 1189-1206.

Syngenta Foundation, 2011. Agricultural Index Insurance Initiative.

Touchan, R., Anchukaitis, K.J., Meko, D.M., Attalah, S., Baisan, C., Aloui, A., 2008. Long term context for recent drought in northwestern Africa. Geophysical Research Letters 35

Touchan, R., Anchukaitis, K.J., Meko, D.M., Sabir, M., Attalah, S., Aloui, A., 2011. Spatiotemporal drought variability in northwestern Africa over the last nine centuries. Climate Dynamics 37 (1-2), 237-252.

Trærup, S., 2012. Informal networks and resilience to climate change impacts: a collective approach to index insurance. Global Environmental Change 22, 255-267.

Urrutia, R.B., Lara, A., Villalba, R., Christie, D.A., Le Quesne, C., Cuq, A., 2011. Multicentury tree ring reconstruction of annual streamflow for the Maule River watershed in south central Chile. Water Resources Research 47.

van der Schrier, G., Barichivich, J., Briffa, K.R., Jones, P.D., 2013. A scPDSI-based global dataset of dry and wet spells for 1901-2009. Journal of Geophysical Research - Atmospheres, http://dx.doi.org/10.1002/jgrd.50355.

Willis, K., Bailey, R., Bhagwat, S., Birks, H., 2010. Biodiversity baselines, thresholds and resilience: testing predictions and assumptions using palaeoecological data. Trends in Ecology \& Evolution 25, 583-591.

Wils, T.H.G., Sass-Klaassen, U.G.W., Eshetu, Z., Braeuning, A., Gebrekirstos, A., Couralet, C., Robertson, I., Touchan, R., Koprowski, M., Conway, D., Briffa, K.R., Beeckman, H., 2011. Dendrochronology in the dry tropics: the Ethiopian case. Trees-Structure and Function 25, 345-354.

Woodhouse, C., Lukas, J., 2006. Drought, tree rings and water resource management in Colorado. Canadian Water Resources Journal 31, 297-310. 